Weed Science 2017 65:41-51

(C) Weed Science Society of America, 2016

\title{
Characterization of Wisconsin Giant Ragweed (Ambrosia trifida) Resistant to Cloransulam
}

\author{
Stacey M. Marion, Vince M. Davis, and David E. Stoltenberg*
}

A giant ragweed population with putative resistance to cloransulam was identified in a long-term corn-soybean rotation located in southern Wisconsin. The population represented the first potential instance of giant ragweed resistance to acetolactate synthase (ALS) inhibitors in the state. Seeds were collected from several plants and pooled for subsequent experiments. Whole-plant dose-response experiments showed a high level of resistance ( $>500$-fold) of the resistant $(\mathrm{R})$ accession to cloransulam compared with a sensitive $(S)$ accession. In vivo ALS bioassays showed that the target enzyme was 10.6- to 13.6-fold less sensitive to cloransulam in $\mathrm{R}$ than in $\mathrm{S}$ plants. Partial sequence analysis of the ALS gene found a tryptophan-to-leucine substitution at the 574 amino acid position (W574L) in the R phenotype. To better understand the potential fitness costs associated with the target-site substitution, replacement series experiments performed under greenhouse conditions characterized the relative growth, development, and fecundity of the $\mathrm{R}$ accession compared with an $\mathrm{S}$ accession in the absence of cloransulam. Growth over time did not differ between the $\mathrm{R}$ and $\mathrm{S}$ accessions for plant height during the vegetative phase (21 to $98 \mathrm{~d}$ after planting [DAP]) or for plant leaf area (21 to $80 \mathrm{DAP})$. At the estimated maximum, proportional shoot dry mass of each accession did not differ from theoretical proportions representing competitive equivalence, indicating no difference in vegetative competitive ability. Fecundity of $R$ plants $\left(430 \pm 53\right.$ seeds plant $\left.^{-1}\right)$ did not differ from that of $S$ plants $\left(451 \pm 47\right.$ seeds plant $\left.^{-1}\right)$, nor did seed viability ( 74 to $75 \%$ across accessions). This is the first report of equal competitive ability, fecundity, and seed viability between giant ragweed accessions $\mathrm{R}$ or $\mathrm{S}$ to cloransulam. The results suggest that the cloransulam resistance trait may persist and spread in the giant ragweed field population over time, even in the absence of selection by cloransulam.

Nomenclature: Cloransulam, corn, Zea mays L., giant ragweed, Ambrosia trifida L. AMBTR, soybean, Glycine max (L.) Merr.

Key words: Acetolactate synthase, fitness, herbicide resistance, triazolopyrimidine herbicides.

Giant ragweed is one of the most problematic weeds in midwestern annual cropping systems (Harrison et al. 2001; Kruger et al. 2009; Regnier et al. 2016). Rapid biomass accumulation, adaptation to a range of successional habitats, and prolonged emergence periods contribute to the success of giant ragweed as an agricultural weed (Bassett and Crompton 1982; Harrison et al. 2007; Schutte et al. 2012). Further contributing to the competitive nature of giant ragweed is its evolved resistance to herbicides. Herbicide-resistant giant ragweed is found in the United States and Canada, with 20 confirmed biotypes in the United States and two in Canada (Heap 2016). Of these biotypes, 13 are resistant to glyphosate, five are resistant to acetolactate synthase (ALS) inhibitors, and four show multiple resistance to both

DOI: $10.1614 /$ WS-D-16-00083.1

* First, second, and third authors: Graduate Research Assistant, Assistant Professor, and Professor, Department of Agronomy, University of Wisconsin-Madison, 1575 Linden Drive, Madison, WI 53706. Corresponding author's E-mail: destolte@wisc.edu herbicides. Although the use of ALS inhibitors decreased following the introduction of glyphosateresistant cropping systems (National Research Council 2010), an increase in glyphosate resistance may actually be an incentive to growers to increase the use of ALS inhibitors. Cloransulam is particularly effective among ALS inhibitors for giant ragweed management in soybean and is an important option for the management of glyphosate-resistant giant ragweed (Davis et al. 2014; Vink et al. 2012).

Resistance to ALS inhibitors is not unique to giant ragweed; more weed species (158) are resistant to ALS inhibitors than any other herbicide group worldwide (Heap 2016). This herbicide group targets the ALS enzyme, thus preventing synthesis of branched-chain amino acids and ultimately starving the plant (Saari et al. 1994). In most cases, resistance to ALS inhibitors has been attributed to reduced sensitivity of the target ALS enzyme (Tranel and Wright 2002). To date, there are few cases of metabolic-conferred resistance to ALS inhibitors (Corbett and Tardif 2006). Several target-site 
mutations have been identified that confer resistance to at least one ALS-inhibiting herbicide family; however, the level of resistance conferred is variable among families (Heap 2016). The most common substitutions include those replacing proline at the 197 position and a tryptophan-to-leucine substitution at the 574 amino acid position (W574L) (Tranel et al. 2015). The W574L substitution relative to an Arabidopsis thaliana reference is the only known mutation to confer resistance to ALS inhibitors in giant ragweed (Patzoldt and Tranel 2002).

Mutations conferring herbicide resistance often involve mutations in major metabolic pathways, and therefore it is hypothesized that the mutation may have a detrimental effect on fitness. Holt and Thill (1994) concluded that alterations of the ALS enzyme affect plant growth and development but these changes may or may not result in a measurable difference in plant fitness. Tardif et al. (2006) found that the W574L substitution in Powell amaranth (Amaranthus powellii S. Wats.) was associated with reduced aboveground biomass and seed production; however, the same mutation in annual bluegrass (Poa annua L.) was associated with greater inflorescence and seed production but did not affect relative growth rate compared with an $S$ biotype (Cross et al. 2015). The effect of target-site alterations on plant fitness is variable depending on the weed species and the specific alteration and therefore should not be generalized (Vila-Aiub et al. 2009).

We identified a giant ragweed population in south-central Wisconsin (Columbia County) that showed putative resistance to cloransulam. The population was found in a long-term corn-soybean rotation with a history of cloransulam and flumetsulam use in soybean and flumetsulam use in corn. Our objectives were to (1) quantify the response of this putative-resistant giant ragweed population to cloransulam, (2) determine the mechanism of resistance, and (3) determine the potential effects of the resistance trait(s) on competitive ability, fecundity, and seed viability.

\section{Materials and Methods}

Seed Sources. Seeds were collected from several putative-resistant plants ( $\mathrm{R}$ accession) and pooled in fall 2008 from the University of Wisconsin-Madison (UW-Madison) Arlington Agricultural Research Station in Colombia County, WI $\left(43^{\circ} 18^{\prime} 9.47^{\prime \prime} \mathrm{N}\right.$, $\left.89^{\circ} 20^{\prime} 43.32^{\prime \prime} \mathrm{W}\right)$. Seeds were also collected from putative-sensitive plants ( $\mathrm{S}$ accession) and pooled from treatments in which ALS-inhibiting herbicides had not been applied in the previous $10 \mathrm{yr}$. Seed samples were cleaned in an air-column separator and stored at $-20 \mathrm{C}$ until conditioning for experiments. Prior to use in experiments, seeds were stratified in cold, wet sand at 4 to $5 \mathrm{C}$ for 8 to $12 \mathrm{wk}$ to break dormancy (Westhoven et al. 2008). Following stratification, embryos were isolated from the achene and involucre following the methods of Schutte et al. (2012) to improve germination rates. For competitive growth and fecundity experiments, seed number was increased for both $R$ and $S$ accessions by growing groups of plants of either accession to maturity in isolated greenhouses. Seeds were harvested, stored, and conditioned as described above.

Whole-Plant Dose Response. Whole-plant cloransulam dose-response experiments were conducted at the UW-Madison greenhouses to quantify the resistance level of the $R$ accession relative to the $S$ accession. Isolated embryos were planted $2 \mathrm{~cm}$ deep in potting medium (Metro Mix $366 \mathrm{P}$, Scott-Sierra Horticultural Products, Marysville, $\mathrm{OH}$ ) in 48-cell plastic trays, with one embryo planted per cell. When the first true leaves emerged, seedlings were transplanted into potting medium (as described above) in $10 \mathrm{~cm}$ diameter by $13 \mathrm{~cm}$ tall plastic pots. Plants were grown under a $12.5 \mathrm{~h}$ light and $11.5 \mathrm{~h}$ dark cycle at 30 and $25 \mathrm{C}$, respectively. The light cycle was supplemented with artificial light $(1000 \mathrm{~W}$ high-pressure sodium, P. L. Light System, Beamsville, ON, Canada). Plants were watered daily and fertilized (380 to $400 \mathrm{ppm} \mathrm{N}$; Peter's Professional Water Soluble Fertilizer, Dublin, $\mathrm{OH}$ ) once weekly. All pots containing plants were rerandomized twice weekly to minimize the effects of microenvironmental variation within the greenhouse.

At the four- to six-node stage (approximately $15 \mathrm{~cm}$ tall plants), $\mathrm{R}$ plants were treated with cloransulam (FirstRate ${ }^{\circledR}$ 84DF, Dow AgroSciences, Indianapolis, IN) at 0 (nontreated check), 0.1765, $1.765,17.65,176.5$, and $1,765 \mathrm{~g}$ ai ha ${ }^{-1}$. Sensitive plants were treated with cloransulam at $0,0.1765$, $0.8825,1.765,17.65$, and $176.5 \mathrm{~g}$ ai ha ${ }^{-1}$. All treatments included $0.25 \%(\mathrm{v} / \mathrm{v})$ nonionic surfactant (Activator 90, Loveland Products, Loveland, CO) and $2.24 \mathrm{~kg} \mathrm{ha}^{-1}$ ammonium sulfate (AMS, Cornbelt ${ }^{\circledR}$ Premium AMS, Van Diest Supply, Webster City, IA). Treatments were applied in a stationary pot sprayer equipped with an even flat-fan spray nozzle (TeeJet $8002 \mathrm{E}$, Spraying Systems, Wheaton, IL) calibrated to deliver $187 \mathrm{~L} \mathrm{ha}^{-1}$ spray solution at the level of the plant canopy. After treatment, plants 
were returned to the greenhouse and maintained in the environmental conditions described above. The experimental design was a completely randomized design with eight replications, and the experiment was repeated four times. The experimental unit was one plant. Shoot mass was harvested $28 \mathrm{~d}$ after treatment, dried at $60 \mathrm{C}$ until constant mass was achieved, and weighed.

Shoot dry mass data were subjected to nonlinear regression using the best-fit model procedure following the methods of Price et al. (2012) and Knezevic et al. (2007). Regression parameters for the $S$ accessions were estimated using a four-parameter log-logistic equation:

$$
Y=c+\{d-c / 1+\exp [b(\log x-\log e)]\}
$$

where $b$ is the relative slope of the curve at $e$ (the inflection point), $c$ is the lower asymptote, and $d$ is the upper asymptote (Knezevic et al. 2007). For symmetric functions, $e$ is equal to the $\mathrm{ED}_{50}$ value, the effective dose of herbicide that decreases shoot biomass by $50 \%$ relative to nontreated plants. The dose-response model was estimated using the 'drc' package (Ritz and Streibig 2005) using R Statistical Language Software ( $\mathrm{R}$ Development Core Team 2014; R Foundation for Statistical Computing, Wien, Austria). A lack-of-fit $F$-test was performed to test similarity of curves (Ritz et al. 2006). Residuals were checked for normality and homogeneity of variance. Responses (aboveground dry shoot mass plant ${ }^{-1}$ ) at discrete doses were tested for differences among the $\mathrm{R}$ and $S$ accessions using ANOVA $(P \leq 0.05)$.

In Vivo ALS Activity. Plants were grown under greenhouse conditions as described above. The response of in vivo ALS activity to cloransulam in $\mathrm{R}$ and $\mathrm{S}$ plants was measured using modified methods of Rainbolt et al. (2005). A stock incubation solution was prepared with $500 \mu \mathrm{M} 1,1$-cyclopropanedicarboxylic acid, 10\% (v/v) Murashige \& Skoog salt media in de-ionized $\mathrm{H}_{2} \mathrm{O}, 10 \mathrm{mM}$ $\mathrm{KH}_{2} \mathrm{PO}_{4}$, and $5.0 \mathrm{~g} \mathrm{~L}^{-1}$ L-alanine. An aliquot of the stock incubation solution was used to prepare treatment doses of $10^{-6}, 10^{-5}, 10^{-4}, 10^{-3}, 10^{-2}, 0.1$, and $1 \mu \mathrm{M}$ cloransulam. Each treatment dose $(100 \mu \mathrm{l})$ was pipetted into a well of a 96-well plate. Fourteen leaf disks were removed from the youngest fully emerged leaf of each plant (four to seven nodes) using a $5 \mathrm{~mm}$ diameter cork borer. Seven leaf disks were used to test each plant at each of the seven cloransulam doses, and seven leaf disks were used as a paired nontreated control. Each treatment was replicated twice per experiment. A single leaf disk was placed in each of the assay wells, with the exception of a single row per plant containing only incubation solution, which was used as an adjustment factor accounting for the absorbance values of the reagents used. No leaf disks were added to wells in this row. Plates were incubated under fluorescent light $(150 \mu \mathrm{mol}$ photons $\mathrm{m}^{-2} \mathrm{~s}^{-1}$ ) for $24 \mathrm{~h}$ at $20 \mathrm{C}$. After incubation, plates were frozen at $-20 \mathrm{C}$ overnight and thawed at $60 \mathrm{C}$ for $15 \mathrm{~min}$. Twenty-five $\mu \mathrm{l}$ of $\mathrm{H}_{2} \mathrm{SO}_{4}$ was added to each well, and the plate was incubated at 60 $\mathrm{C}$ for $20 \mathrm{~min}$, after which $150 \mu \mathrm{l}$ of a solution containing $2.5 \mathrm{~g} \mathrm{~L}^{-1}$ creatine and $25 \mathrm{~g} \mathrm{~L}^{-1} \alpha$-napthenol in $2 \mathrm{~N} \mathrm{NaOH}$ was pipetted into each assay well. Plates were incubated at $60 \mathrm{C}$ for $15 \mathrm{~min}$ to facilitate color change. After incubation, $200 \mu \mathrm{l}$ from each well were transferred to a microtiter plate. Absorbance at $535 \mathrm{~nm}$ was measured using a Tecan spectrophotometer. Absorbance measurements were corrected by subtracting the average absorbance values from the calculated adjustment factor. Enzyme activity was calculated as a percent of the absorbance of the nontreated paired controls. The experiment was repeated four times.

Net absorbance data were subjected to nonlinear regression using the best-fit model procedure as described above. Regression parameters were estimated using a three-parameter log-logistic equation:

$$
Y=d / 1+\exp [b(\log x-\log e)]
$$

where $b$ is the relative slope of the curve at $e, d$ is the upper asymptote, and $e$ is the inflection point (Knezevic et al. 2007). For symmetric functions, $e$ is equal to the $\mathrm{EC}_{50}$ value, the effective concentration of herbicide that inhibits enzyme activity by $50 \%$ relative to nontreated plants. Parameter estimates were compared among experiments, and if differences were not significant, data were pooled.

Molecular Basis of Resistance. DNA was extracted from 10 plants each of the $R$ and $S$ accessions (two to three node growth stage) using a DNA isolation kit (DNeasy Plant Mini Kit, Qiagen, Valencia, CA) and a modified protocol from Park et al. (2012). DNA samples were stored at $-20 \mathrm{C}$ until used for subsequent molecular analysis.

Polymerase chain reaction (PCR) amplification and automated sequencing of the PCR products were performed using a modified protocol by Patzoldt and Tranel (2002). A smaller region of the ALS gene (Region B) was amplified where single point mutations conferring resistance to ALS inhibitors have been identified in giant ragweed and related species (Guttieri et al. 1996; Patzoldt and 
Tranel 2002; Patzoldt et al. 2001; Tranel et al. 2004; Zheng et al. 2005). The forward and reverse primers used were 5'-ATGAACGTTCAAGAGTTAGC-3' and 5'-CCTTCGGTGATCACATCCTTGAA-3'. The PCR reaction mix contained $40 \mathrm{ng}$ DNA, $400 \mathrm{nM}$ each of forward and reverse primers, $0.2 \mathrm{mM}$ dNTP's, $1.5 \mathrm{mM} \mathrm{MgCl}_{2}$, and 1 unit of Taq polymerase in $1 \times$ supplied buffer, in a final volume of $25 \mu \mathrm{l}$. The thermocycler protocol followed a $3 \mathrm{~min}$ incubation at $95 \mathrm{C}$ followed by 35 cycles of $0.5 \mathrm{~min}$ at $95 \mathrm{C}, 1 \mathrm{~min}$ at $50 \mathrm{C}, 1 \mathrm{~min}$ at $72 \mathrm{C}$, and a $5 \mathrm{~min}$ extension at $72 \mathrm{C}$. PCR products were isolated by gel electrophoresis using a 1.2\% TAE agarose gel containing $0.5 \mu \mathrm{g} \mathrm{ml}^{-1}$ ethidium bromide and visualized using an ultraviolet light. Prior to sequencing, PCR products were cleaned using ExoSAP-IT For PCR Product Cleanup (Affymetrix, USB, Santa Clara, CA) following the manufacturer's instructions. The sequencing reaction was performed using ABI Prism Big Dye Terminator Kit and sequenced using an ABI 3730xl DNA Analyzer at the UW-Madison Biotechnology Center DNA Sequencing Facility. Sequence data were aligned and analyzed using Sequencher 5.3 software (Gene Codes, Ann Arbor, MI).

Competitive Growth and Fecundity. Seedlings were transplanted into $55 \mathrm{~cm}$ diameter $(10 \mathrm{~L})$ pots containing potting soil medium (as described above) after emergence of the first true leaves. Plants were grown under greenhouse conditions, watered, and fertilized as described above. Pots were rerandomized weekly to minimize the effects of microenvironmental variation in the greenhouse until $70 \mathrm{~d}$ after planting (DAP), at which time pollen shed began.

Replacement series experiments (Cousens 1991; Park et al. 2003) were conducted at one giant ragweed plant density (33 plants $\mathrm{m}^{-2}$ ) and five ratios of $\mathrm{R}$ to $\mathrm{S}$ plants (\% R:\% S, 0:100, 25:75, 50:50, 75:25, and 100:0; eight plants total per ratio). The experimental design was completely randomized, and each treatment was replicated three times. The total number of plants per experiment was 120 . The experiment was repeated.

Nondestructive measurements of plant height and estimated leaf area were taken from 21 to $98 \mathrm{DAP}$, at which time plants were at or near maximum biomass and leaf area. Leaf area per plant was estimated from the length and width of each leaf according to the following equation:

$$
\mathrm{LA}=\sum(L W S)
$$

where LA is the total leaf area per plant, $L$ is the leaf length, $W$ is the leaf width, and $S$ is a species-specific coefficient that represents the proportional area of a rectangle occupied by a leaf (Moechnig et al. 2003). The $S$ coefficient used for giant ragweed was 0.52 , as previously reported by Glettner and Stoltenberg (2015). As plants matured, senescing biomass was collected, dried at $60 \mathrm{C}$ to constant mass, and weighed. A subsample of plants from each experiment $(n=24)$ were bagged (polypropylene pollination bags, 198 by $213 \mathrm{~cm}$, Vilutis and Company, Frankfort, IL) for seed collection. At physiological maturity, seeds were harvested, and plant height was measured prior to cutting the shoot at the soil surface. Shoots were dried at $60 \mathrm{C}$ to constant mass, and weighed. Shoot mass at physiological maturity was combined with dried senesced biomass to estimate total shoot dry mass at maximum vegetative growth. Seeds were collected from a subset of mature plants $(n=24)$ from each experiment. Seed yield was determined as total $\mathrm{g}$ seed plant $^{-1}$, number of seeds plant $^{-1}$, and $\mathrm{g}$ seed $^{-1}$. Seed viability was determined by categorizing a subsample of seeds $(n=50)$ into categories described by Harrison et al. (2001): intact viable and intact nonviable (for both of which involucres contained fully formed seeds, with viability determined by tetrazolium assay) and empty involucre (no seed or not fully formed seed inside). The tetrazolium assay (Peters 2000) was performed by imbibing unconditioned seeds for $18 \mathrm{~h}$ in distilled water, cutting seeds in half lengthwise, and soaking cut-side down in a $0.1 \%(\mathrm{v} / \mathrm{v})$ aqueous solution of 2,3,5-triphenyl-tetrazolium chloride for $18 \mathrm{~h}$ at room temperature and examining for uniform staining (Glettner and Stoltenberg 2015).

The natural log of plant height and estimated leaf area was regressed over time and fit with a quadratic regression model with the use of the function ' $1 \mathrm{~m}$ ' in $\mathrm{R}$ Statistical Language software (R Development Core Team 2014; R Foundation for Statistical Computing, Wien, Austria). Residuals were checked for normality and homogeneity of variance. A linear model was used to determine whether regression coefficients for either growth parameter differed between the $\mathrm{R}$ and $\mathrm{S}$ accessions at the $5 \%$ significance level.

Shoot dry mass data at estimated maximum plant biomass were analyzed using the 'lm' package in $\mathrm{R}$. The de Wit method (De Wit and van den Bergh 1965) was used to compare the proportional shoot dry mass of $\mathrm{R}$ and $\mathrm{S}$ accessions to theoretical mass under conditions of competitive equivalence. A 95\% confidence interval was used to determine deviation from theoretical mass at each planting ratio. Seed yield and seed viability data demonstrated 
heterogeneous variances, and therefore these data were analyzed using a Welch's $t$-test $(P \leq 0.05)$.

\section{Results and Discussion}

Whole-Plant Dose Response. Dose-response model parameters did not differ across the four repeated experiments; therefore, data were pooled across the experiments for analysis. The best-fit model describing the $S$ accession was a fourparameter log-logistic model. The $\mathrm{ED}_{50}$ estimate was $3.0 \mathrm{~g}$ ai $\mathrm{ha}^{-1}$ cloransulam for the $S$ accession (Table 1). A response curve accurately describing an $\mathrm{ED}_{50}$ for the $\mathrm{R}$ accession could not be determined, as shoot mass of $\mathrm{R}$ plants treated with the maximum dose $\left(1,765 \mathrm{~g}\right.$ ai ha $^{-1}, 100$ times the labeled rate) was reduced only by $40 \%$ relative to the nontreated control. Therefore, the $\mathrm{ED}_{50}$ was estimated to be greater than $1,765 \mathrm{~g}$ ai ha ${ }^{-1}$ (Table 1). Shoot mass did not differ between nontreated $\mathrm{R}$ and $\mathrm{S}$; however, at discrete doses $\left(1.765,17.65\right.$, and $176.5 \mathrm{~g}$ ai ha $\left.{ }^{-1}\right)$ shoot mass differed between $\mathrm{R}$ and $\mathrm{S}$ accessions, indicating a differential response to cloransulam (Figure 1). The $\mathrm{R}$ accession was also tested for multiple resistance to glyphosate and was found to be sensitive (unpublished data).

In Vivo ALS Activity. Regression model parameters for $\mathrm{R}$ and $\mathrm{S}$ accessions differed among four repeated bioassays, but parameters did not differ between each of the two sets of these bioassays. Therefore, data were pooled across each set of bioassays for analysis and referred to as Experiments 1 and 2. Differential ALS activity between R and S accessions in response to cloransulam was observed in both experiments (Figure 2). The effective concentrations of cloransulam that inhibited ALS activity $50 \%$ relative to nontreated plants $\left(\mathrm{EC}_{50}\right)$ were 10.6- and 13.6-fold greater for $\mathrm{R}$ than $S$ plants in Experiments 1 and 2, respectively (Table 2). This differential sensitivity of the ALS enzyme to cloransulam suggested that resistance is likely conferred by an altered target enzyme. These results do not exclude non-target-site-based resistance (NTSR);

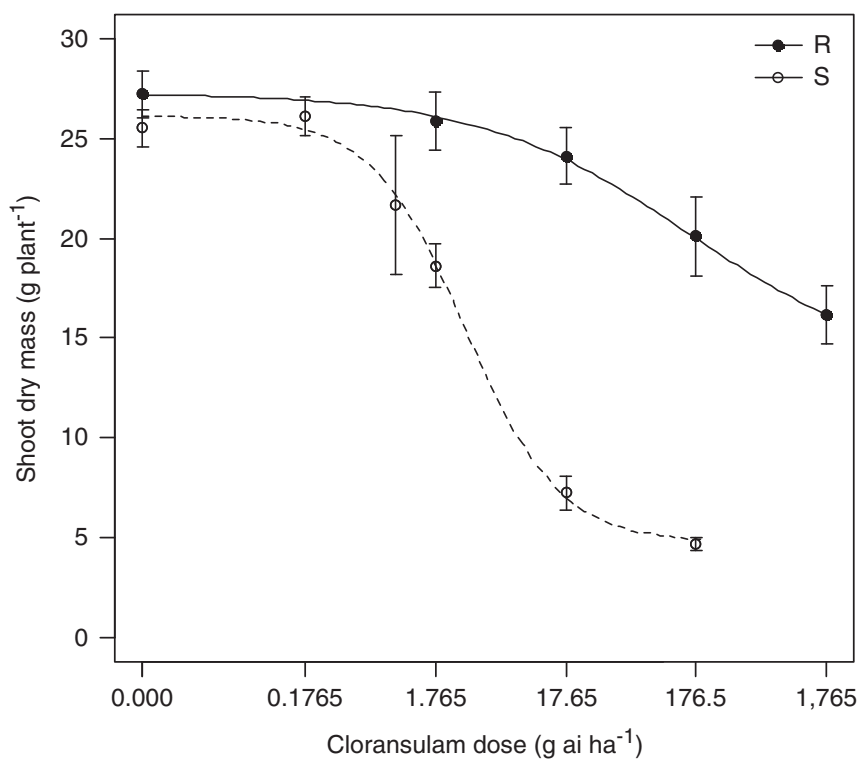

Figure 1. Shoot dry mass for putative-resistant (R) and putativesensitive (S) giant ragweed $28 \mathrm{~d}$ after treatment with cloransulam. All treatments included $0.25 \%(\mathrm{v} / \mathrm{v})$ nonionic surfactant and $2.25 \mathrm{~kg} \mathrm{ha}^{-1}$ ammonium sulfate. Predicted responses are described by $Y=14.59+\{27.29-14.59 / 1+\exp [0.59(\log (x)-$ $\log (92.12)]\}$ and $Y=4.70+\{26.13-4.70 / 1+\exp [1.19(\log (x)-$ $\log (3.04)]\}$ for $\mathrm{R}$ and $\mathrm{S}$, respectively. Vertical bars represent standard error of the mean. Data were pooled from repeated experiments for analysis. Dose-response model parameter values are shown in Table 1.

Table 1. Dose-response model parameters based on shoot dry mass of putative cloransulam-resistant (R) and cloransulam-sensitive $(S)$ giant ragweed accessions $28 \mathrm{~d}$ after treatment with cloransulam. ${ }^{\text {a }}$

\begin{tabular}{|c|c|c|c|c|}
\hline \multirow[b]{3}{*}{ Accession } & \multicolumn{4}{|c|}{ Dose-response model parameters ${ }^{\mathrm{b}}$} \\
\hline & \multirow[b]{2}{*}{$b$} & \multicolumn{2}{|c|}{ Shoot dry mass } & \multirow[b]{2}{*}{$\mathrm{ED}_{50}$} \\
\hline & & $c$ & $d$ & \\
\hline $\mathrm{R}$ & - & - & - & $\begin{array}{l}\text { g ai ha }{ }^{-1} \\
>1,765^{\mathrm{c}}\end{array}$ \\
\hline S & $1.2(0.3)$ & $4.7(1.3)$ & $26.1(0.8)$ & $3.0(0.7)$ \\
\hline
\end{tabular}

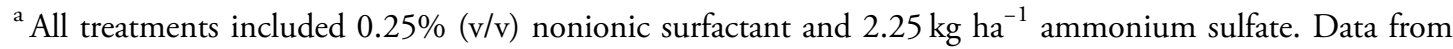
repeated experiments were pooled for analysis. Standard errors are shown in parentheses. Dose-response curves are shown in Figure 1.

${ }^{\mathrm{b}} b$, relative slope around $e\left(\mathrm{ED}_{50}\right) ; c$, lower asymptote; $d$, upper asymptote; $\mathrm{ED}_{50}$, effective dose of cloransulam that decreased shoot dry mass by $50 \%$ relative to nontreated control plants. A dash (-) indicates parameter value not estimated.

${ }^{\mathrm{c}}$ Estimated value is greater than maximum dose $\left(1,765 \mathrm{~g}\right.$ ai ha $\left.{ }^{-1}\right)$ applied. 


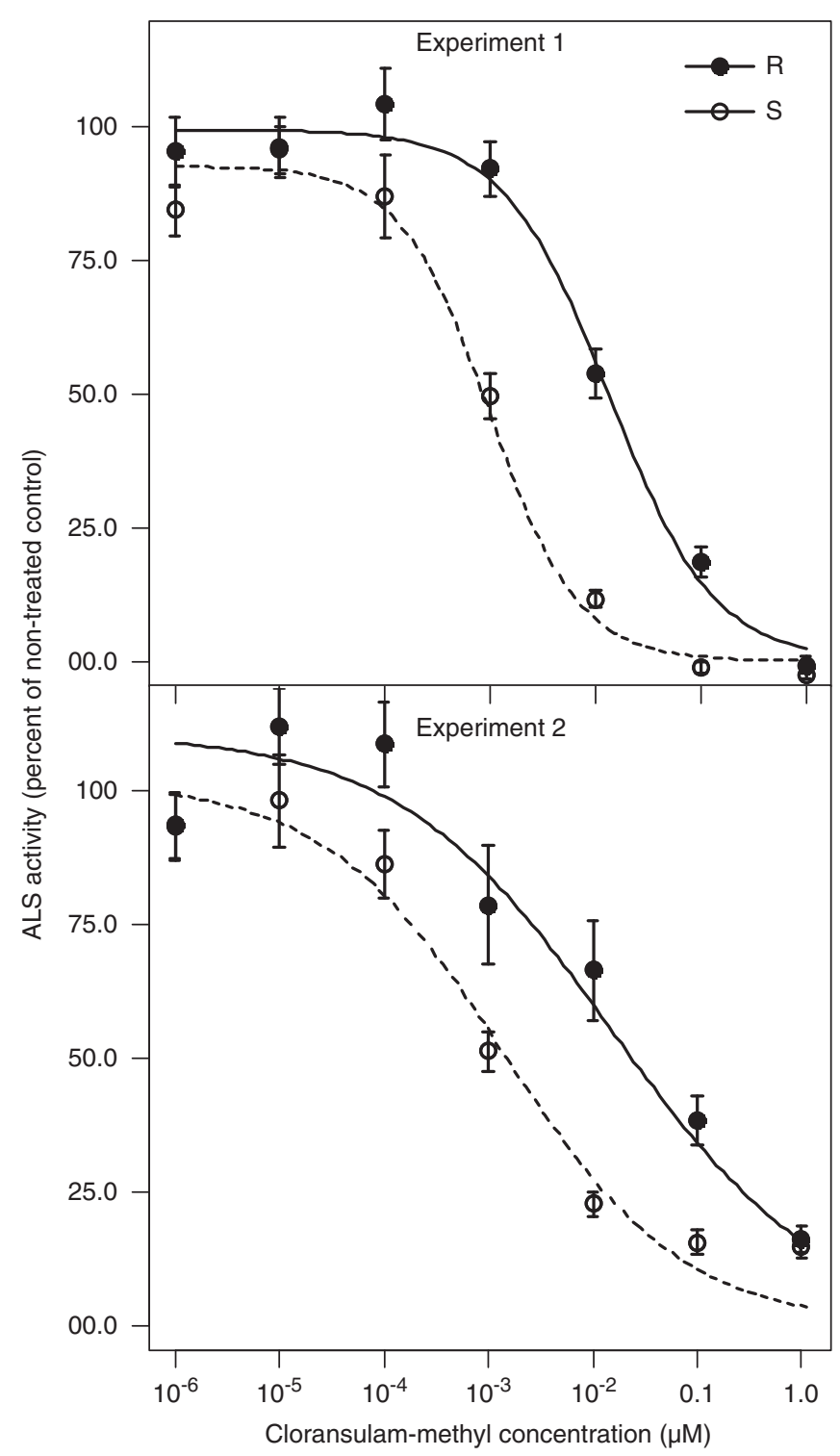

Figure 2. In vivo ALS enzyme activity (expressed as a percent of a paired control treatment) in response to cloransulam concentration in resistant $(\mathrm{R})$ and sensitive $(\mathrm{S})$ giant ragweed plants. Model parameters differed between experiments; therefore, data from repeated experiments were analyzed separately. Predicted responses for $\mathrm{R}$ and $\mathrm{S}$ accessions in Experiment 1 are described by the equations $Y=(0.9938 / 1)+\exp [0.8684(\log (x)-\log$ $(0.0133)]$ and $Y=(0.9254 / 1)+\exp [1.029(\log (x)-\log (0.0010)]$, respectively. Predicted responses for $\mathrm{R}$ and $\mathrm{S}$ accessions in Experiment 2 are described by the equations $Y=(1.106 /$ $1)+\exp [0.4258(\log (x)-\log (0.0149)]$ and $Y=(1.016 / 1)+\exp$ $[0.5071(\log (x)-\log (0.0014)]$, respectively. Vertical bars represent standard error of the mean. Dose-response model parameter values are shown in Table 2 .

however, NTSR to ALS inhibitors has rarely been reported in broadleaf weeds (Délye 2013).

Molecular Basis of Resistance. A polymorphic region of the ALS gene was amplified based on prior research identifying this region as containing point mutations that confer resistance to ALS inhibitors (Tranel and Wright 2002; Tranel et al. 2015). Following sequence editing, a consensus sequence contained a total of 345 base pairs. Within the partial $A L S$ sequence, six nucleotide substitutions (Table 3) were identified that resulted in two missense (Table 4) and four silent amino acid substitutions when translated.

A substitution of a $\mathrm{G}$ to $\mathrm{T}$ nucleotide conferred a tryptophan-to-leucine substitution at the 574 position relative to an Arabidopsis thaliana reference sequence (Table 4). All $\mathrm{R}$ plants tested were heterozygous for the amino acid substitution, in which one allele retained the $G$ nucleotide, and one allele contained the $\mathrm{T}$ mutation. The tryptophan-toleucine substitution (W574L) was associated with the $\mathrm{R}$ accession, and we therefore identified this substitution as the molecular basis of resistance to cloransulam. A W574L substitution has been documented in several broadleaf and grass weed species (McCullough et al. 2016; McElroy et al. 2013; Patzoldt and Tranel 2002; Powles and Yu 2010; Tranel and Wright 2002; Yu et al. 2008). It is the second most common of eight amino acid substitutions identified as conferring resistance to one or more ALS-inhibiting herbicide families (Tranel et al. 2015) following a proline substitution at the 197 position. A W574L mutation is the only confirmed substitution conferring resistance to ALS inhibitors in either common ragweed (Ambrosia artemisiifolia L.) or giant ragweed (Tranel et al. 2015). In common ragweed, a W574L substitution confers a high level of resistance to both triazolopyrimidine and imidazolinone herbicides (Patzoldt et al. 2001; Zheng et al. 2005). In giant ragweed, however, there is limited $A L S$ sequence information. Patzoldt and Tranel (2002) found that a W574L substitution conferred resistance to triazolopyrimidine, imidazolinone, and sulfonylurea herbicides in a population of giant ragweed from Indiana; however, ALS sensitivity was not assessed quantitatively. In both ragweed species, heterozygosity and homozygosity of the Leu $_{574}$ substitution has been documented (Patzoldt and Tranel 2002; Zheng et al. 2005). Zheng et al. (2005) concluded that the Leu $_{574}$ allele acted as a dominant allele conferring ALS inhibitor resistance in common ragweed, such that only one allele is necessary to confer resistance. These results suggest that the Leu $_{574}$ similarly acts as a dominant allele in giant ragweed.

A second missense mutation resulted in a tryptophan-to-cysteine amino acid substitution at 
Table 2. Dose-response model parameters based on acetolactate synthase (ALS) activity in leaf tissue of cloransulam-resistant $(\mathrm{R})$ and cloransulam-sensitive $(\mathrm{S})$ giant ragweed accessions $24 \mathrm{~h}$ after treatment with cloransulam. ${ }^{\mathrm{a}}$

\begin{tabular}{|c|c|c|c|c|c|}
\hline \multirow[b]{3}{*}{ Experiment } & \multirow[b]{3}{*}{ Accession } & \multicolumn{3}{|c|}{ Dose-response model parameters ${ }^{b}$} & \multirow[b]{3}{*}{$\mathrm{EC}_{50} \mathrm{R}: \mathrm{S}$} \\
\hline & & \multirow[b]{2}{*}{$b$} & \multicolumn{2}{|l|}{ ALS activity } & \\
\hline & & & $d$ & $\mathrm{EC}_{50}$ & \\
\hline 1 & $\mathrm{R}$ & $0.87(0.13) \mathrm{a}$ & $\begin{array}{l}\text { \% of control } \\
99.4(2.7) \mathrm{a}\end{array}$ & $\begin{array}{l}\mu \mathrm{M} \text { cloransulam } \\
0.013(0.003) \mathrm{a}\end{array}$ & $13.6(3.73)$ \\
\hline & $S$ & $1.03(0.21) \mathrm{a}$ & $92.5(3.3) \mathrm{a}$ & $0.001(0.000) \mathrm{b}$ & \\
\hline 2 & $\mathrm{R}$ & $0.43(0.08) \mathrm{b}$ & $111(5.0) b$ & $0.015(0.006) \mathrm{a}$ & $10.6(6.41)$ \\
\hline & $S$ & $0.51(0.12) \mathrm{b}$ & $102(7.0) \mathrm{b}$ & $0.001(0.001) \mathrm{b}$ & \\
\hline
\end{tabular}

\footnotetext{
${ }^{\text {a }}$ Standard errors are shown in parentheses. Dose-response curves are shown in Figure 2.

${ }^{\mathrm{b}} b$, relative slope around $e\left(\mathrm{EC}_{50}\right) ; d$, upper asymptote; $\mathrm{EC}_{50}$, effective concentration of cloransulam that decreased ALS activity by $50 \%$ relative to nontreated plants. Estimates followed by the same letter within a column and within an experiment do not differ at the $5 \%$ level of significance.
}

Table 3. Nucleotide polymorphisms inferred from alignments of partial $A L S$ sequence data for cloransulam-resistant (R) and cloransulam-sensitive $(S)$ giant ragweed plants.

\begin{tabular}{lccccccc}
\hline & & \multicolumn{6}{c}{ Nucleotide polymorphisms } \\
\cline { 2 - 8 } Accession & Plant no. & 1761 & 1776 & 1837 & 1855 & 1861 & 1961 \\
\hline R & Consensus & G & A & C & T & G & C \\
R & 1 & $\mathrm{~K}$ & $\mathrm{R}$ & $\mathrm{Y}$ & $\mathrm{Y}$ & $\mathrm{R}$ & $\mathrm{Y}$ \\
$\mathrm{R}$ & 2 & $\mathrm{~K}$ & $\mathrm{R}$ & $\mathrm{Y}$ & $\mathrm{Y}$ & $\mathrm{R}$ & - \\
$\mathrm{R}$ & 3 & $\mathrm{~K}$ & $\mathrm{R}$ & $\mathrm{Y}$ & $\mathrm{Y}$ & $\mathrm{R}$ & - \\
$\mathrm{R}$ & 4 & $\mathrm{~K}$ & $\mathrm{R}$ & $\mathrm{Y}$ & $\mathrm{Y}$ & $\mathrm{R}$ & - \\
$\mathrm{R}$ & 5 & $\mathrm{~K}$ & $\mathrm{R}$ & $\mathrm{Y}$ & $\mathrm{Y}$ & $\mathrm{R}$ & - \\
$\mathrm{R}$ & 6 & $\mathrm{~K}$ & $\mathrm{R}$ & $\mathrm{Y}$ & $\mathrm{Y}$ & $\mathrm{R}$ & - \\
$\mathrm{R}$ & 7 & $\mathrm{~K}$ & $\mathrm{R}$ & $\mathrm{Y}$ & $\mathrm{Y}$ & $\mathrm{R}$ & - \\
$\mathrm{R}$ & 8 & $\mathrm{~K}$ & $\mathrm{R}$ & $\mathrm{Y}$ & $\mathrm{Y}$ & $\mathrm{R}$ & - \\
$\mathrm{R}$ & 9 & $\mathrm{~K}$ & $\mathrm{R}$ & $\mathrm{Y}$ & $\mathrm{Y}$ & $\mathrm{R}$ & - \\
$\mathrm{S}$ & 10 & $\mathrm{~K}$ & $\mathrm{R}$ & $\mathrm{Y}$ & $\mathrm{Y}$ & $\mathrm{R}$ & - \\
$\mathrm{S}$ & 11 & - & - & - & - & - & $\mathrm{T}$ \\
$\mathrm{S}$ & 12 & - & - & - & $\mathrm{Y}$ & $\mathrm{R}$ & - \\
$\mathrm{S}$ & 13 & - & $\mathrm{R}$ & $\mathrm{Y}$ & $\mathrm{Y}$ & $\mathrm{R}$ & - \\
$\mathrm{S}$ & 14 & - & - & - & - & - & $\mathrm{T}$ \\
$\mathrm{S}$ & 15 & - & - & - & - & - & $\mathrm{T}$ \\
$\mathrm{S}$ & 16 & - & - & - & - & - & - \\
$\mathrm{S}$ & 17 & - & $\mathrm{R}$ & $\mathrm{Y}$ & $\mathrm{Y}$ & $\mathrm{R}$ & - \\
$\mathrm{S}$ & 18 & - & - & - & - & - & - \\
$\mathrm{S}$ & 19 & - & $\mathrm{R}$ & $\mathrm{Y}$ & $\mathrm{Y}$ & $\mathrm{R}$ & $\mathrm{Y}$ \\
\hline & 20 & - & - & - & - & - & - \\
\hline
\end{tabular}

${ }^{a}$ Polymorphisms are indicated by nucleotide position based on the Arabidopsis thaliana acetolactate synthase mRNA sequence retrieved from Genbank (gil30693053|reflNM_114714.2).

${ }^{\mathrm{b}} \mathrm{K}, \mathrm{R}$, and $\mathrm{Y}$ indicate heterozygous nucleotides $\mathrm{G} / \mathrm{T}, \mathrm{A} / \mathrm{G}$, and $\mathrm{C} / \mathrm{T}$, respectively.

${ }^{\mathrm{c}} \mathrm{A}$ dash (-) indicates identity with the consensus sequence.

the 579 position (Y579C) relative to an Arabidopsis thaliana reference sequence (Table 4). The Cys 579 substitution was not unique to the $\mathrm{R}$ accession, and
Table 4. Amino acid polymorphisms inferred from alignments of partial sequence data of $A L S$ for cloransulam-resistant (R) and cloransulam-sensitive $(S)$ giant ragweed plants.

\begin{tabular}{lclc}
\hline & & \multicolumn{2}{c}{ Amino acid polymorphisms } \\
\cline { 2 - 4 } Accession & Plant no. & 574 & 579 \\
\hline R & 1 & Trp/Leu & Tyr/Cys \\
R & 2 & Trp/Leu & Tyr/Cys \\
R & 3 & Trp/Leu & Tyr/Cys \\
R & 4 & Trp/Leu & Tyr/Cys \\
R & 5 & Trp/Leu & Tyr/Cys \\
R & 6 & Trp/Leu & Tyr/Cys \\
R & 7 & Trp/Leu & Tyr/Cys \\
R & 8 & Trp/Leu & Tyr/Cys \\
R & 9 & Trp/Leu & Tyr/Cys \\
R & 10 & Trp/Leu & Tyr/Cys \\
S & 11 & Trp & Tyr \\
S & 12 & Trp & Tyr \\
S & 13 & Trp & Tyr/Cys \\
S & 14 & Trp & Tyr \\
S & 15 & Trp & Tyr \\
S & 16 & Trp & Tyr \\
S & 17 & Trp & Tyr/Cys \\
S & 18 & Trp & Tyr \\
S & 19 & Trp & Tyr/Cys \\
S & 20 & Trp & Tyr \\
\hline
\end{tabular}

${ }^{\text {a }}$ Polymorphisms are indicated by amino acid number based on the Arabidopsis thaliana ALS sequence (Sathasivan et al. 1990). Two amino acids indicate that the $A L S$ nucleotide sequence was heterozygous within the associated codon.

therefore did not likely confer resistance to cloransulam. However, all $\mathrm{R}$ plants tested exhibited an allele for the Y579C substitution, whereas this allele was found in three out of $10 \mathrm{~S}$ plants (S-13, S-17, and S-19 in Table 4). Patzoldt et al. (2001) previously identified the Y579C substitution in a 
population of ALS-resistant giant ragweed; however, the substitution was not associated with the $\mathrm{R}$ phenotype. This study concludes that the $\mathrm{R}$ accession was highly resistant to cloransulam and that resistance was conferred by a W574L amino acid substitution.

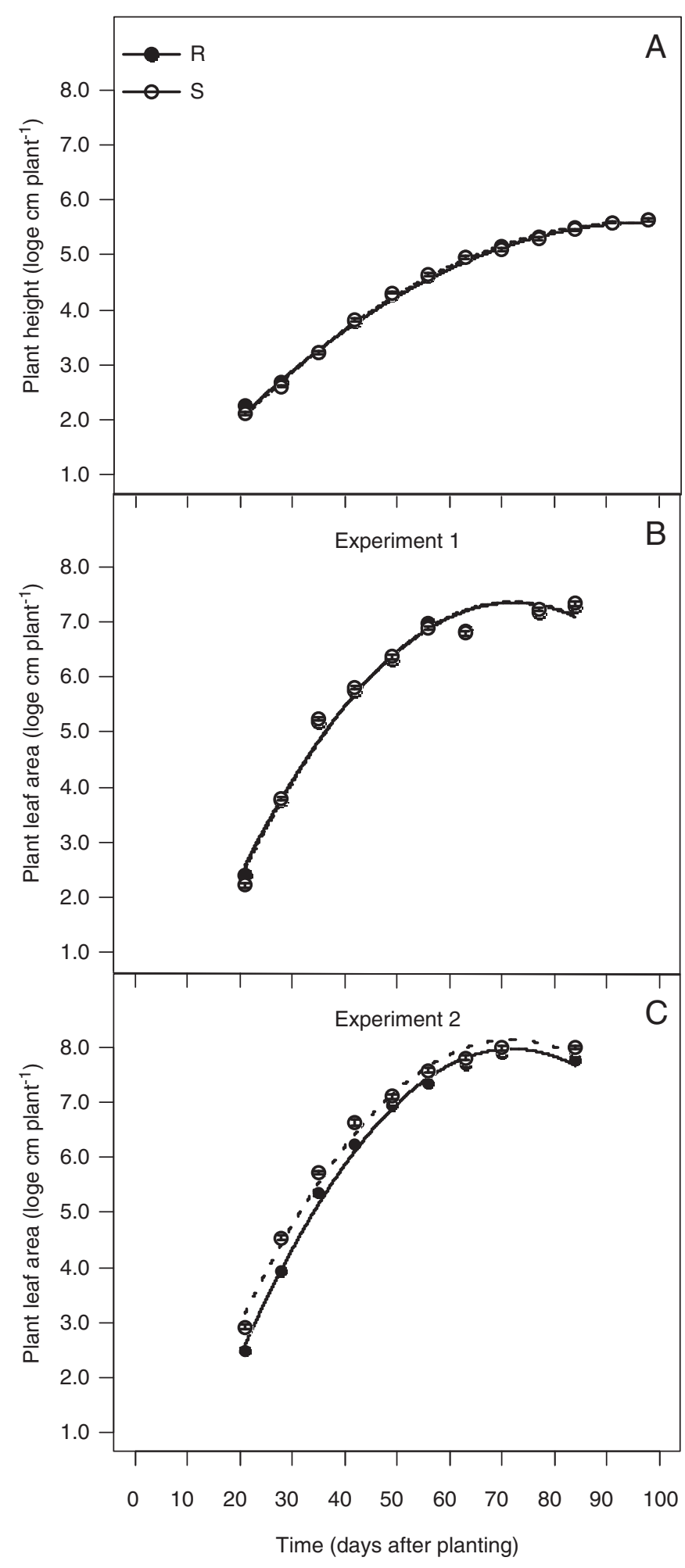

Vegetative Growth and Development. The experiment by treatment interaction for plant height over time was not significant (unpublished data); therefore, data from repeated experiments were pooled for analysis. Plant height during the vegetative phase (21 to 98 DAP) did not differ between the $\mathrm{R}$ and $\mathrm{S}$ accessions (Figure $3 \mathrm{~A}$ ). The experiment by treatment interaction for plant leaf area was significant (unpublished data); therefore, data were analyzed separately for each experiment. Similar to plant height, leaf area did not differ between the $\mathrm{R}$ and $\mathrm{S}$ accessions over time (21 to $80 \mathrm{DAP}$ ) (Figure 3B,C).

In mixed ratios of $\mathrm{R}$ to $\mathrm{S}$ plants (\% R:\% S, 25:75, $50: 50,75: 25)$ the treatment by accession interaction for shoot dry biomass was not significant $(P=0.69)$, inferring no competitive interaction between the $\mathrm{R}$ and $\mathrm{S}$ accessions. At each ratio of $\mathrm{R}$ to $\mathrm{S}$ plants, the proportional shoot dry mass of either accession did not differ from theoretical proportions representing competitive equivalence, indicating no difference in competitive ability (Figure 4).

Previous research has not determined the effects of ALS inhibitor resistance on giant ragweed growth and development. In other species, resistance to ALS inhibitors has been associated with variable effects on plant growth and development. In ALS inhibitorresistant Powell amaranth, Tardif et al. (2006) found that a W574L substitution was associated with detrimental effects on plant growth, including slower development and reduced biomass production. They found that sensitive plants consistently outperformed resistant plants when grown under competitive conditions. However, the W574L substitution has not been associated with apparent differences in

Figure 3. Natural logarithm of (A) plant height and (B and C) leaf area over time for cloransulam-resistant $(\mathrm{R})$ and cloransulamsensitive $(\mathrm{S})$ giant ragweed accessions grown under competitive conditions in the greenhouse. Plant height data from repeated experiments were pooled for analysis. Plant leaf area data from repeated experiments were analyzed separately. (A) Plant height over time is described by $Y=-0.01596+0.1142 x-0.0005824$ $x^{2}\left(\mathrm{r}^{2}=0.97\right)$ and $Y=-0.1778+0.1205 x-0.0006292 x^{2}$ $\left(\mathrm{r}^{2}=0.95\right)$ for $\mathrm{R}$ and $\mathrm{S}$ accessions, respectively. (B) Plant leaf area over time in Experiment 1 is described by $Y=-2.122+0.2622 x-0.001816 x^{2} \quad\left(\mathrm{r}^{2}=0.94\right)$ and $Y=-2.292+0.2680 x-0.001859 x^{2}\left(\mathrm{r}^{2}=0.95\right)$ for $\mathrm{R}$ and $\mathrm{S}$ accessions, respectively. (C) Plant leaf area over time in Experiment 2 is described by $Y=$ $-2.740+0.2978 x-0.002071 x^{2}\left(\mathrm{r}^{2}=0.96\right)$ and $Y=-1.807+0.2772 x-0.001933 x^{2}\left(\mathrm{r}^{2}=0.96\right)$ for $\mathrm{R}$ and $\mathrm{S}$ accessions, respectively. Vertical bars represent standard error of the mean. 
growth and development in other species. Yu et al. (2010) identified a biotype of rigid ryegrass (Lolium rigidum Gaudin) with no difference in growth compared with sensitive biotypes. Similarly, Légère et al. (2013) found no evidence of differential growth between ALS inhibitor-resistant and ALS inhibitor-sensitive biotypes of kochia [Kochia scoparia (L.) Schrad]. Although Li et al. (2013) found that the W574L substitution decreased ALS activity in ALS inhibitor-resistant wild radish (Raphanus raphanistrum L.), plant growth was not affected. Other common mutations conferring resistance to ALS inhibitors have been associated with both decreased and increased ALS activity compared with sensitive wild types; however, effects on plant

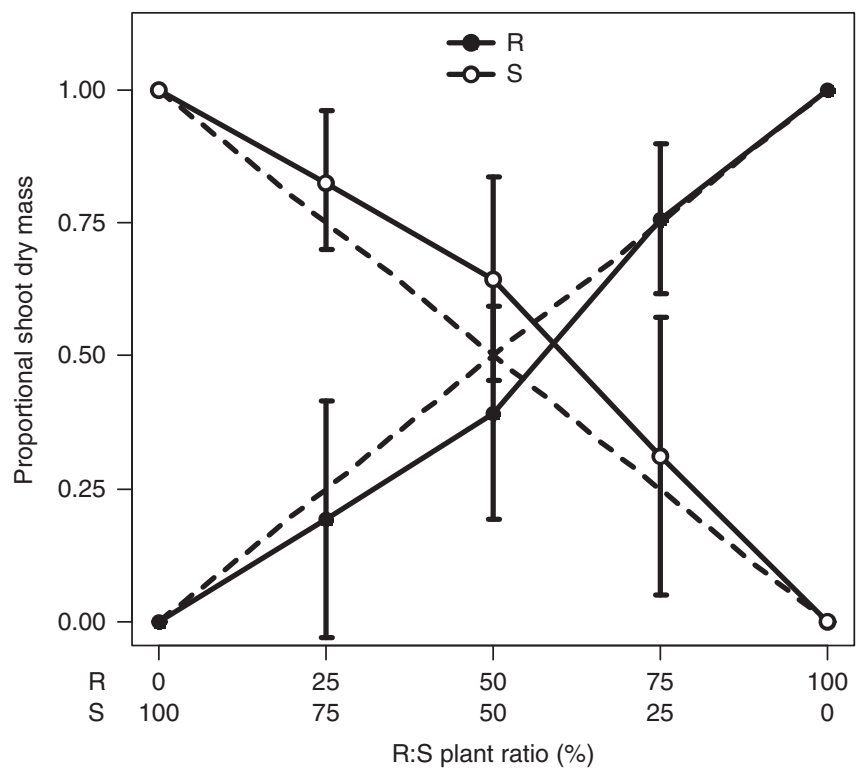

Figure 4. Replacement series diagram for shoot dry mass at physiological maturity for cloransulam-resistant (R) and cloransulam-sensitive $(S)$ giant ragweed accessions grown under competitive conditions in the greenhouse. Data from repeated experiments were pooled for analysis. Dashed lines indicate theoretical competitive equivalence between accessions. Vertical bars represent $95 \%$ confidence intervals. growth were variable or not apparent ( $\mathrm{Li}$ et al. 2013; Vila-Aiub et al. 2009; Yu et al. 2010).

Fecundity and Seed Viability. The experiment by treatment interaction was not significant for fecundity or seed viability (unpublished data); therefore, data from repeated experiments were pooled for analysis. Each of the metrics of fecundity (total g seed plant ${ }^{-1}$, number of seeds plant ${ }^{-1}$, and $\mathrm{g} \mathrm{seed}^{-1}$ ) and seed viability (percent intact viable, intact nonviable, and empty involucre) did not differ between $\mathrm{R}$ and $\mathrm{S}$ accessions (Table 5). These results suggest that the W574L resistance trait is not associated with any apparent detrimental effects on seed quantity or quality of the $\mathrm{R}$ accession.

Tardif et al. (2006) reported markedly decreased seed production in an ALS inhibitor-resistant biotype of Powell amaranth compared with a sensitive biotype when grown in either competitive or noncompetitive conditions. In contrast, Cross et al. (2015) found that ALS inhibitor resistance in annual bluegrass was associated with greater inflorescence and seed production compared with $S$ plants. These results and those of previous research suggest that target-site alterations conferring ALS resistance can affect ALS activity and have pleiotropic effects on plant fitness (Li et al. 2013; VilaAiub et al. 2009; Yu et al. 2010); however, they also suggest that the effects on plant growth and reproduction are inconsistent among species and may be subtle or not apparent.

The life history traits and demography of giant ragweed promote the spread of a resistance trait, particularly if the trait is not associated with a fitness cost. In outcrossing species like giant ragweed, nuclear-inherited dominant traits such as the W574L substitution (Zheng et al. 2005) have the potential to spread rapidly (Maxwell et al. 1990). Heritability of the resistance trait and success of offspring were not investigated in this study.

Table 5. Fecundity and seed viability of cloransulam-resistant $(\mathrm{R})$ and cloransulam-sensitive $(\mathrm{S})$ giant ragweed accessions grown under competitive conditions in the greenhouse. ${ }^{a}$

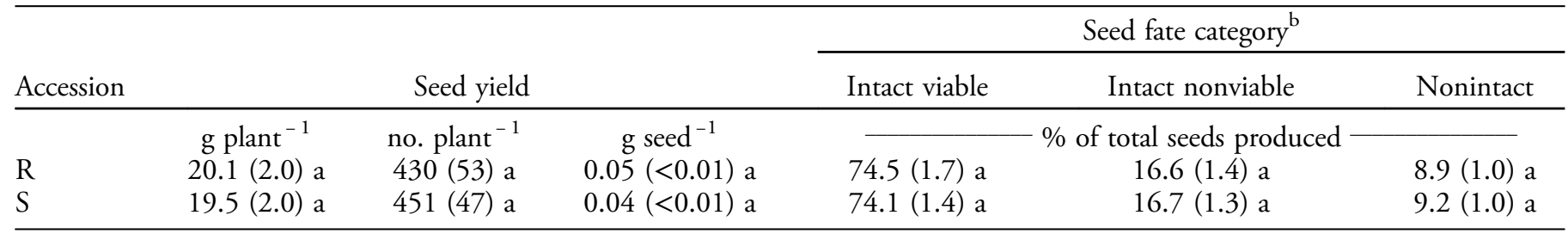

\footnotetext{
${ }^{a}$ Data from repeated experiments were pooled for analysis. Standard error of the mean is shown in parentheses. Means followed by the same letter within a column do not differ at the $5 \%$ level of significance as determined by a Welch's $t$-test.

${ }^{\mathrm{b}}$ Intact viable and nonviable involucres contained fully formed seeds with viability of embryo determined by tetrazolium assay; nonintact, no seed, or incompletely formed seed.
} 
If heritability of the trait and offspring survival are not affected by the resistance trait, these findings would suggest that the frequency of the resistance trait will be maintained even in the absence of selection pressure by a herbicide (Jasieniuk and Maxwell 1994). Further contributing to the maintenance of a resistance trait is the broad abundance of giant ragweed across the landscape (Regnier et al. 2016) and its continuance in the soil seedbank (Harrison et al. 2007). Seed dormancy beyond a growing season facilitates gene flow among multiple generations (Hartnett et al. 1987), leading to persistence of a resistance trait.

The rate of spread of a resistance trait may also be affected by the dominance level of fitness costs. Previous research has shown that fitness costs associated with herbicide resistance may differ between heterozygous and homozygous resistant plants, depending on the dominance level of fitness costs, which can be recessive, underdominant, or dominant (Roux et al. 2004). In mutant lines of Arabidopsis thaliana resistant to the ALS inhibitor chlorsulfuron, Roux et al. found that the dominance level of fitness costs was recessive, suggesting that the spread of resistance alleles for chlorsulfuron would spread faster under agronomic conditions compared with resistance alleles with dominant or underdominant fitness costs, which the authors found in lines resistant to the synthetic auxin herbicide 2,4-D. As noted above, plants in our competitive growth and fecundity experiments were grown from seeds collected from R or $S$ plants that had been grown in separate groups, respectively, in isolated greenhouses. Consequently, $\mathrm{R}$ plants in our experiments could have been either heterozygous or homozygous for the cloransulam resistance allele. If the dominance level of potential fitness costs associated with cloransulam resistance was recessive, it would facilitate rapid spread of the resistance allele in a predominantly outcrossing species such as giant ragweed.

The interaction of life cycle characteristics and selection pressures, including management, will ultimately determine the persistence of resistance traits within a population. A survey of the occurrence and distribution of glyphosate- and/or cloransulammethyl-resistant giant ragweed in Ontario, Canada, demonstrated a rapid increase in the occurrence and geographical distribution of resistant biotypes over a period of just $3 \mathrm{yr}$ (Follings et al. 2013). This instance should be interpreted as a cautionary tale of the potential spread of resistance traits when conditions are favorable. Given the life history traits of giant ragweed favoring persistence in the soil seedbank for periods of several years (Harrison et al. 2007), tactics aimed at managing giant ragweed resistance to ALS inhibitors should be implemented prior to its evolution, since once established there are no apparent biological selective forces to decrease its proportion in the population.

\section{Acknowledgments}

The authors would like to thank the students who assisted us in this project: Rachel Bouressa, Cole Cook, Mariana Debernardini, Courtney Glettner, and Joseph Zimbric.

\section{Literature Cited}

Bassett IJ, Crompton CW (1982) The biology of Canadian weeds. 55. Ambrosia trifida L. Can J Plant Sci 62:1003-1010

Corbett CL, Tardif FJ (2006) Detection of resistance to acetolactate synthase inhibitors in weeds with emphasis on DNA-based techniques: a review. Pest Manag Sci 62:584-597

Cross RN, McCarty LB, McElroy JS, Tharavil N, Bridges WC Jr. (2015) Comparison of enzyme and growth characteristics in ALS-inhibitor susceptible and resistant annual bluegrass (Poa annua) biotypes. Weed Sci 63:220-228

Cousens R (1991) Aspects of the design and interpretation of competition (interference) experiments. Weed Technol 5:664-673

Davis V, Jensen B, Nice G, Renz M, Smith D (2014) Pest management in Wisconsin field crops-2015. Madison, WI: Division of Cooperative Extension of the University of Wisconsin Extension A3646. 320 p

Délye C (2013) Unraveling the genetic bases of non-target-site-based resistance (NTSR) to herbicides: a major challenge for weed science in the forthcoming decade. Pest Manag Sci 69:176-187

De Wit CT, van den Bergh JP (1965) Competition between herbage plants. Neth J Agric Sci 13:212-221

Follings J, Soltani N, Robinson DE, Tardif FJ, Lawton MB, Sikkema PH (2013) Distribution of glyphosate and cloransulam-methyl resistant giant ragweed (Ambrosia trifida L.) populations in southern Ontario. Ag Sci 4:570-576

Glettner CE, Stoltenberg DE (2015) Noncompetitive growth and fecundity of Wisconsin giant ragweed resistant to glyphosate. Weed Sci 63:273-281

Guttieri MJ, Eberlein CV, Mallory-Smith CA, Thill DC (1996) Molecular genetics of target-site resistance to acetolactate synthase inhibiting herbicides. Pages 10-16 in Brown TM ed, Molecular Genetics and Evolution of Pesticide Resistance. Washington, DC: American Chemical Society

Harrison SK, Regnier EE, Schmoll JT, Harrison JM (2007) Seed size and burial effects of giant ragweed (Ambrosia trifida) emergence and seed demise. Weed Sci 55:16-22

Harrison SK, Regnier EE, Schmoll JT, Webb JE (2001) Competition and fecundity of giant ragweed in corn. Weed Sci 49:224-229

Hartnett DC, Hartnett BB, Bazzaz FA (1987) Persistence of Ambrosia trifida populations in old fields and responses to successional changes. Am J Bot 74:1239-1248

Heap IM (2016) The International Survey of Herbicide Resistant Weeds. http://www.weedscience.org/In.asp. Accessed March 8, 2016

50 - Weed Science 65, January-February 2017 
Holt JS, Thill DC. (1994) Growth and productivity of resistant plants. Pages 299-316 in Powles SB, Holtum JAM, eds. Herbicide Resistance in Plants: Biology and Biochemistry. Boca Raton, FL: Lewis

Jasieniuk M, Maxwell B (1994) Population genetics and the evolution of herbicide resistance in weeds. Phytoprotection 75:25-35

Knezevic SZ, Streibig JC, Ritz C (2007) Utilizing R software package for dose-response studies: the concept and data analysis. Weed Technol 21:840-848

Kruger GR, Johnson WG, Weller SC, Owen MDK, Shaw DR, Wilcut JW, Jordan DL, Wilson RG, Bernards ML, Young BG (2009) U.S. grower views on problematic weeds and changes in weed pressure in glyphosate-resistant corn, cotton, and soybean cropping systems. Weed Technol 23:162-166

Légère A, Stevenson FC, Beckie HJ, Warwick SI, Johnson EN, Hrynewich B, Lozinski C (2013) Growth characterization of kochia (Kochia scoparia) with substitutions at Pro197 or Trp574 conferring resistance to acetolactate synthaseinhibiting herbicides. Weed Sci 61:267-276

Li M, Yu Q, Han H, Vila-Aiub M, Powles S B (2013) ALS herbicide resistance mutations in Raphanus raphanistrum: evaluation of pleiotropic effects on vegetative growth and ALS activity. Pest Manag Sci 69:689-695

Maxwell BD, Roush ML, Radesevich SR (1990) Predicting the evolution and dynamics of herbicide resistance in weed populations. Weed Technol 4:2-13

McCullough PE, McElroy JS, Yu J, Zhang H, Miller TB, Chen S, Johnston CR, Czarnota (2016) ALS-resistant spotted spurge (Chamaesyce maculate) confirmed in Georgia. Weed Sci 64:216-222

McElroy JS, Flessner ML, Wang Z, Dane F, Walker RH, Wehtje GR (2013) A Trp 574 to Leu amino acid substitution in the ALS gene of annual bluegrass (Poa annua) is associated with resistance to ALS-inhibiting herbicides. Weed Sci 61:21-25

Moechnig MJ, Boerboom CM, Stoltenberg DE, Binning LK (2003) Growth interactions in communities of lambsquarters (Chenopodium album), giant foxtail (Setaria faberi) and corn. Weed Sci 51:363-370

[NRC] National Research Council. (2010). Impact of Genetically Engineered Crops on Farm Sustainability in the United States. Committee on the Impact of Biotechnology on Farm-Level Economics and Sustainability. Washington, DC: National Academies Press. 249 p

Park SE, Benjamin LR, Watkinson AR (2003) The theory and application of plant competition models: an agronomic perspective. Ann Bot 92:741-748

Patzoldt WL, Tranel PJ (2002) Molecular analysis of cloransulam resistance in a population of giant ragweed. Weed Sci 50:299-305

Patzoldt WL, Tranel PJ, Alexander AL, Schmitzer PR (2001) A common ragweed population resistant to cloransulam-methyl. Weed Sci 49:485-490

Peters J (2000) Section A-B, Asteraceae. In Peters J, ed. Tetrazolium Testing Handbook Contribution 29 (2nd edn, Lincoln, NE: Association of Official Seed Analysts. 302 p

Price WJ, Shafii B, Seefeldt SS (2012) Estimation of dose-response models for discrete and continuous data in weed science. Weed Tech 26:587-601

Powles SB, Yu Q (2010) Evolution in action: plants resistant to herbicides. Ann Rev Plant Biol 61:317-347

Rainbolt CR, Thill DC, Zemetra RS, Shaner DL (2005) Imidazolinone-resistant wheat acetolactate synthase in vivo response to imazamox. Weed Sci 19:539-548
Regnier EE, Harrison SK, Loux MM, Holloman C, Venkatesh R, Diekmann F, Taylor R, Ford RA, Stoltenberg DE, Hartzler RG, Davis AS, Schutte BJ, Cardina J, Mahoney KJ, Johnson WG (2016) Certified crop advisors' perceptions of giant ragweed (Ambrosia trifida) distribution, herbicide resistance, and management in the Corn Belt. Weed Sci 64:361-377

Ritz C, Cedergreen N, Jensen JE, Streibig JC (2006) Relative potency in nonsimilar dose-response curves. Weed Sci 54:407-412

Roux F, Gasquez J, Reboud X (2004) The dominance of the herbicide resistance cost in several Arabidopsis thaliana mutant lines. Genetics 166:449-460

Saari LL, Cotterman JIC, Thill DC (1994) Resistance to acetolactate synthase inhibiting herbicides. Pages 83-139 in Powles SB \& Holtum JAM eds, Herbicide Resistance in Plants: Biology and Biochemistry. Ann Arbor, MI: Lewis

Sathasivan K, Haughn GW, Murai N (1990) Nucleotide sequence of a mutant acetolactate synthase gene from an imidazolinone-resıstant Arabidopsis thaliana var. Colombia. Nucl Acids Res 18:2188 doi:10.1093/nar/18.8.2188

Schutte BJ, Regnier EE, Harrison SK (2012) Seed dormancy and adaptive seedling emergence timing in giant ragweed (Ambrosia trifida). Weed Sci 60:19-26

Tardif FJ, Rajcan I, Costea M (2006) A mutation in the herbicide target site acetohydroxyacid synthase produces morphological and structural alterations and reduces fitness in Amaranthus powellii. New Phytol 169:251-264

Tranel PJ, Wright TR (2002) Resistance of weeds to ALSinhibiting herbicides: What have we learned? Weed Sci 50:700-712

Tranel PJ, Jiang W, Patzoldt WL, Wright TR (2004) Intraspecific variability of the acetolactate synthase gene. Weed Sci 52:236-241

Tranel PJ, Wright TR, Heap IM (2015). Mutations in herbicideresistant weeds to ALS inhibitors. http://www.weedscience. com. Accessed March 20, 2015

Vila-Aiub MM, Neve P, Powles SB (2009) Fitness costs associated with evolved herbicide resistance alleles in plants. New Phytol 184:751-767

Vink JP, Soltani N, Robinson DE, Tardif FJ, Lawton MB, Sikkema PH (2012) Glyphosate-resistant giant ragweed (Ambrosia trifida L.) control with preplant herbicides in soybean (Glycine max L.). Can J Plant Sci 92:913-922

Westhoven AM, Davis VM, Gibson KD, Weller SC, Johnson WG (2008b) Field presence of glyphosate-resistant horseweed (Conyza canadensis), common lambsquarters (Chenopodium album), and giant ragweed (Ambrosia trifida) biotypes with elevated tolerance to glyphosate. Weed Technol 22:544-548

$\mathrm{Yu}$ Q, Han H, Powles SB (2008) Mutations of the ALS gene endowing resistance to ALS-inhibiting herbicides in Lolium rigidum populations. Pest Manag Sci 64:1229-1236

Yu Q, Han H, Vila-Aiub MM, Powles SB (2010) AHAS herbicide resistance endowing mutations: effect on AHAS functionality and plant growth. Exp Bot 61:3925-3934

Zheng D, Patzoldt WL, Tranel PJ (2005) Association of the W574L ALS substitution with resistance to cloransulam and imazamox in common ragweed (Ambrosia artemisiifolia). Weed Sci 53:424-430

Received May 23, 2016, and approved August 17, 2016.

Associate Editor for this paper: Muthukumar $V$. Bagavathiannan, Texas A\&M. 